J. Breath Res. 9 (2015) 047104 http://dx.doi.org/10.1088/1752-7155/9/4/047104

\title{
Increase of methanol in exhaled breath quantified by SIFT-MS following aspartame ingestion
}

\author{
Patrik Španěl $^{1 *}$, Kseniya Dryahina ${ }^{1}$, Petra Vicherková ${ }^{1}$, David Smith ${ }^{2}$ \\ ${ }^{1}$ J. Heyrovsky Institute of Physical Chemistry, Academy of Science of the Czech Republic, \\ Dolejškova 3, 18223 Prague 8, Czech Republic \\ ${ }^{2}$ Institute for Science and Technology in Medicine, School of Medicine, Keele University, \\ Thornburrow Drive, Hartshill, Stoke-on-Trent ST4 7QB, UK
}

E-mail: spanel@jh-inst.cas.cz

Keywords: volatile metabolites, aspartame, methanol, selected ion flow tube mass spectrometry (SIFT-MS)

\begin{abstract}
Aspartame, methyl-L- $\alpha$-aspartyl-L-phenylalaninate, is used worldwide as a sweetener in foods and drinks and is considered to be safe at an acceptable daily intake (ADI) of 40 mg per kg of body weight. This compound is completely hydrolyzed in the gastrointestinal tract to aspartic acid, phenylalanine and methanol, each being toxic at high levels. The objective of the present study was to quantify the volatile methanol component in the exhaled breath of ten healthy volunteers following the ingestion of a single ADI dose of aspartame. Direct on-line measurements of methanol concentration were made in the mouth and nose breath exhalations using selected ion flow tube mass spectrometry, SIFT-MS, several times before aspartame ingestion in order to establish individual pre-dose (baseline) levels and then during two hours post-ingestion to track their initial increase and subsequent decrease. The results show that breath methanol concentrations increased in all volunteers by $1082 \pm 205$ parts-per-billion by volume, ppbv, from their pre-ingestion values, which ranged from 193 to 436 parts-per-billion by volume, ppbv, to peak values ranging from 981-1622 ppbv, from which they slowly decreased. These observations agree quantitatively with a predicted increase of $1030 \mathrm{ppbv}$ estimated using a one-compartment model of uniform dilution of the methanol generated from a known amount of aspartame throughout the total body water (including blood). In summary, an ADI dose of aspartame leads to a $3-6$ fold increase of blood methanol concentration above the individual baseline values.
\end{abstract}




\section{Introduction}

Quantitative analysis of exhaled breath for volatile trace compounds is providing a noninvasive window into physiological and pathophysiological processes, revealing volatile biomarkers of particular diseases and infections, allowing the biochemistry and metabolism of ingested foods and drugs to be traced, and the uptake into the blood stream of ambient toxic compounds to be monitored. All this represents a valuable contribution to medical diagnosis and therapeutic monitoring, the history and development of which are reported in two texts co-edited by Anton Amann [1, 2]. The research work reported in this paper, which quantitatively connects breath methanol with ingested aspartame, is homage to our dear friend and colleague, Anton, in recognition of his pioneering work and enormous contributions to breath analysis, which have laid the foundations to this new area of research.

Aspartame, methyl-L- $\alpha$-aspartyl-L-phenylalaninate, is marketed under several brand names and is widely used as a sweetener additive in cakes, candies and fizzy drinks such as cola []ㅡ. It has been studied widely because of its potential toxicity since it is hydrolyzed in the stomach and in the small intestine to aspartic acid, phenylalanine and methanol. Currently, the acceptable daily intake (ADI) of aspartame in Europe is $40 \mathrm{mg}$ per $\mathrm{kg}$ of body weight (simplified to $\mathrm{mg} / \mathrm{kg}$ in what follows) and in the United States is $50 \mathrm{mg} / \mathrm{kg}$ [4]. Although it has been declared safe at ADI or lower doses $[\underline{5}, \underline{6}]$, connection has been suggested to a wide range of adverse conditions and diseases, including lymphomas and leukemia [7]. The aspartic acid component is connected to neurological disorders including migraine, seizures, epilepsy [8]. Aspartame should not be ingested by suffers from phenylketonuria since it will exacerbate the condition. The methanol product is converted by metabolism to formaldehyde $[\underline{4}, 9]$. It has been suggested that formaldehyde binds to tissue proteins and nucleic acids and this is cumulative; thus, it can represent a hazard to health [9]. Finally, formaldehyde is converted to formic acid that has a longer half-life in the body and is considered to be the primary toxic compound in methanol poisoning [4]].

The amount of methanol produced from the average amounts of aspartame in a normal diet (estimated as $8 \mathrm{mg} / \mathrm{kg}$ by the FDA $[\underline{4}, \underline{10}]$ ) has been observed to result in some rise in blood methanol concentration, but this increase was comparable with the intra-individual differences of endogenous methanol [10]. It is not certain if this amount of methanol is of any concern since it is comparable to its generation from ingested fruit juices, citrus fruits and fermented beverages [11]. However, it was reported that methanol is clearly elevated in blood 
following ingestion of typically $100 \mathrm{mg} / \mathrm{kg}$ doses of aspartame (more than twice ADI). In a 1981 study [12], blood methanol remained below the detection limit (of the analytical technique used) of subjects who ingested $34 \mathrm{mg} / \mathrm{kg}$, but elevation was observed at abuse doses of 100 to $200 \mathrm{mg} / \mathrm{kg}$. Blood analyses were carried out in 6 subjects who ingested aspartame at $200 \mathrm{mg} / \mathrm{kg}$ but, no significant increases in blood formate concentration were noted [12]. In a subsequent 1989 study in which six adults ingested four servings of beverage each containing $600 \mathrm{mg}$ of aspartame over several hours, equivalent to a typical ADI, blood methanol and formate concentrations remained below the limit of detection of the techniques used [13].

Methanol, unlike phenylalanine and aspartic acid, is a very volatile compound that was first detected in exhaled breath more than 50 years ago [14]. It is present in exhaled breath of all human beings [ $\underline{15-17]}$, as is formaldehyde at much lower concentrations [18, 19]. Formic acid is presumably present in breath also, but there are practical reasons why it is difficult to detect and quantify by selected ion flow tube mass spectrometry (SIFT-MS) and proton transfer reaction mass spectrometry (PTR-MS) [20]. Previous SIFT-MS studies of exhaled breath methanol in the general population have shown that concentrations range widely from 32 parts-per-billion by volume, ppbv, to 2319 ppbv [21], with a median value in ppbv reported in specific studies to be 461 [22], 238 [23], 193 [24] and 189 [18]. Later SIFT-MS studies of mouth-exhaled and nose-exhaled breath have shown that the methanol is largely systemic, i.e. it is generated endogenously, being present in the blood stream with little, if any, generated in the oral cavity [19]. These previous results will be referred to again later and compared with those obtained in the present study. The origin of endogenous methanol is usually considered to be by the action of gut bacteria on carbohydrates and sugars with a contribution from the breakdown of ingested aspartame to be expected. The aim of the present study was to quantify, for the first time, the increase of methanol in exhaled breath following an acceptable daily intake (ADI) of aspartame as set by the European Food Safety Authority [25]. 


\section{Materials and methods}

The objective of the study was to establish how the concentration of breath methanol changes after ingestion of an ADI of aspartame by a group of healthy volunteers.

\subsection{Volunteers}

10 healthy volunteers were recruited to the study that was carried out at the J. Heyrovsky Institute of Physical Chemistry in Prague. The biometrics of the individuals in the group are given in Table 1. Ethical permission for the study was obtained from the Ethics Committee of the Science Faculty of Charles University in Prague. All participants were informed of the protocol of the study and each provided informed consent before participating. Exclusion criteria were that volunteers did not suffer from diabetes or phenylketonuria.

\subsection{Aspartame dose.}

The toxicity of aspartame has been thoroughly investigated in animal models and it has been shown that chronic toxicity results at ingestion concentrations of $4000 \mathrm{mg} / \mathrm{kg}$. From the collected data it was concluded that at the currently established ADI of $40 \mathrm{mg} / \mathrm{kg}$ there are no safety concerns [25]. Thus, the volunteers were requested to ingest an amount of aspartame at the safe ADI level as contained in "Irbis sweet" (manufactured by Irbis s.r.o., Slusovice, Czech Republic). This sweetener contains $19.5 \%$ of aspartame together with lactose (major ingredient), croscarmellose and L-leucine. The ingested aspartame dose was prepared as an appropriate number of "Irbis sweet" tablets dissolved in $200 \mathrm{~mL}$ of tap water at a temperature of $15{ }^{\circ} \mathrm{C}$.

\subsection{SIFT-MS analyses of exhaled breath methanol using SIFT-MS}

The selected ion flow tube mass spectrometry (SIFT-MS) technique has been described in detail in several review papers and need not be repeated in depth here [26-28]. The strengths and weaknesses of this analytical technique has been discussed recently [29] and the pitfalls in the approaches to breath analysis in general are reviewed in a very recent paper in the Journal of Breath Research [21]. It is sufficient to say that SIFT-MS analysis involve the chemical ionization by chosen reagent ions $\left(\mathrm{H}_{3} \mathrm{O}^{+}, \mathrm{NO}^{+}, \mathrm{O}_{2}{ }^{+}\right)$of the trace compounds in a breath sample that has been introduced directly into a reactor flow tube. Characteristic analyte ions are produced in the reactions of the reagent ions and the trace neutral analyte molecules in the breath sample and from an in-depth knowledge of this ion chemistry, both the identity of the analyte molecules and, most importantly, their accurate quantification can 
be achieved even in single breath exhalations. It has been shown many times that detection and quantification of methanol in exhaled breath using $\mathrm{H}_{3} \mathrm{O}^{+}$reagent ions is straightforward as long as the common analyte ion of the ever-present isoprene in the breath sample at massto-charge ratio, $\mathrm{m} / \mathrm{z}$, at 69 is excluded from the analysis. These details of methanol analysis have been discussed thoroughly in a recent paper [30]. It is sufficient to note that analysis is performed using the $\mathrm{H}_{3} \mathrm{O}^{+}$reagent ion (mass-to-charge ratio, $\mathrm{m} / \mathrm{z} 19$ ) and its hydrates at $\mathrm{m} / \mathrm{z}$ 37, 55 and 73, and the analyte ions used for methanol analysis are only $\mathrm{CH}_{3} \mathrm{OH}_{2}{ }^{+}(\mathrm{m} / z$ 33) and its monohydrate $\mathrm{CH}_{3} \mathrm{OH}_{2}{ }^{+} \mathrm{H}_{2} \mathrm{O}(m / z 51)$.

The usual approach to breath analysis, when directed towards intervention and pharmacokinetics studies involving ingestion of medicines, therapeutic drugs, isotopically labelled tracers and alcoholic beverages, is first to establish the pre-dose breath concentrations of the targeted volatile compounds to establish the "baseline value" for each of the 10 individuals involved. Thus, in the present study the methanol concentration in the exhaled breath of each of the 10 volunteers was determined in three consecutive single exhalations/inhalations every 15 minutes over one hour before aspartame ingestion. The following breath sampling procedure was used in the present study:

Each volunteer exhaled and inhaled three times consecutively via a disposable cardboard mouthpiece inserted into the SIFT-MS breath sampling adaptor fitted with a flow restricting aperture (4.8 $\mathrm{mm}$ diameter, $4 \mathrm{~mm}$ long). Exhalations and inhalations were of 10 to $15 \mathrm{~s}$ durations. Volunteers were standing during the sampling and avoided any unusual physical activity prior to and during the study. A fraction of the air/breath is sampled from the midstream via a short calibrated capillary and flows through a longer PEEK line and an inlet port into the helium carrier gas of the SIFT-MS instrument for analysis. The entire sampling line is heated to minimise loss of condensable compounds, including methanol and water vapour. The capillary establishes the breath/air sample flow rate at a known value ( $24 \mathrm{~mL} / \mathrm{min}$ in the present experiments), as is essential for accurate metabolite quantification $[\underline{30}, \underline{31}]$. Analysis is performed using the multiple ion monitoring (MIM) mode of SIFT-MS [31]; for methanol, the analyte ions given above are targeted. The water vapour concentration was routinely measured, as is the recommended practice in the SIFT-MS breath studies [ $\underline{30}$, 31], which acts as a check of the correct air/breath sampling rate. Thus, the water vapour must be $>5 \%$ by volume of exhaled breath [30-32]. The last two thirds of each individual exhalation concentration time profile, as identified by the water vapour concentration profile, were selected for the methanol concentration measurement. This sampling procedure was 
repeated following the ingestion of the aspartame at the individual dosage of $40 \mathrm{mg} / \mathrm{kg}$ of body weight, extending the observation time to 2 hours post-ingestion. The average values of the methanol concentrations from the three consecutive exhalations were calculated and tabulated for each volunteer, as were the ambient air methanol concentrations (from inhalations). In addition to mouth exhalations, nose-exhaled concentrations were determined in a similar fashion for volunteers 1 to 4 .

\section{Results}

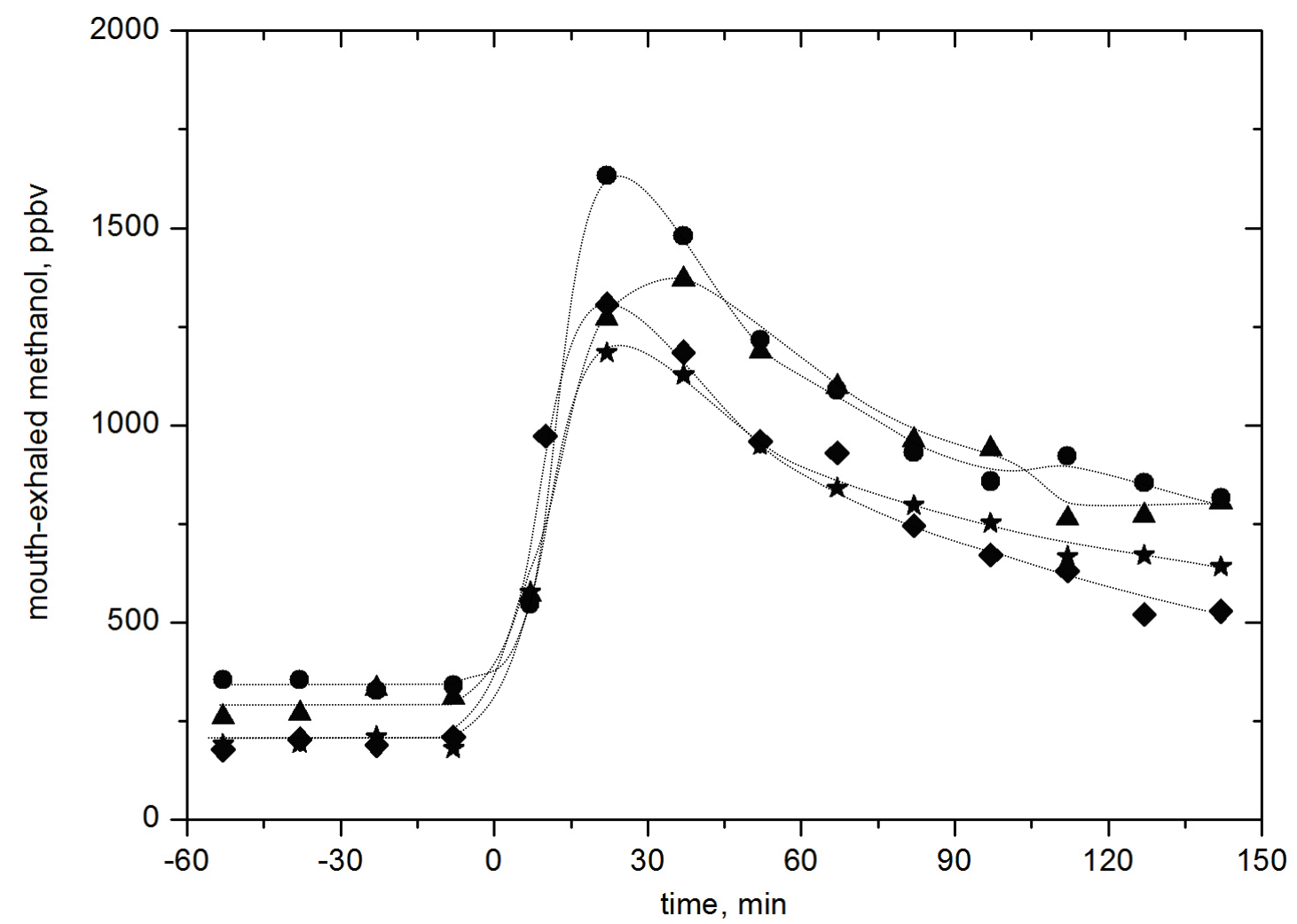

Figure 1 Time profiles of mouth-exhaled methanol concentration in partsper-billion by volume, ppbv, for four volunteers $(1-\bullet, 2-\bullet, 3-\star, 4-\boldsymbol{\Delta})$ before $(\mathrm{P})$ and after ingestion of the aspartame dose at the time indicated by the vertical arrow. The peak post-ingestion (M) mouth-exhaled breath methanol concentrations are indicated by arrows.

The background methanol concentration in the inhaled air during these studies was in the range 50 to $100 \mathrm{ppbv}$. Its contribution to the exhaled breath concentration can be determined using the retention coefficient of 0.29 for methanol, as determined in a recent SIFT-MS study 
[33] and is estimated to be less than $30 \mathrm{ppbv}$ in the exhaled breath, so it was not necessary to correct the data for this. Sample data for the mouth-exhaled methanol concentrations are shown in Figure 1 for volunteers No. 1 - 4 (see Table 1) spanning the time period from the first pre-dose measurements to the last post-dose measurements. The concentration-time profiles for all ten volunteers had similar shapes as those given in Figure 1, but all are not shown for clarity. The time taken for the breath methanol to reach its peak for all ten individuals varied from about 15 to 30 minutes post-ingestion after which it begins to decrease. Interpretation of these trends will be presented in the Discussion section.

The pre-ingestion (P) and the peak post-ingestion (M) mean mouth-exhaled breath methanol concentrations in ppbv are given in Table 1 together with their differences (M-P) that correspond to the maximum increases due to the aspartame ingestion. Also given are the uncertainties in all measurements as determined from the standard error calculated from variation between all data points recorded during the three exhalations [31]. The intraindividual variation observed prior to ingestion was in the range of S.D. 12 to 35 ppbv. The fractional increase in breath methanol due to the aspartame ingestion ranges from 3 to 6 times for this small cohort of healthy individuals, reaching $1470 \mathrm{ppbv}$ in the breath of one volunteer.

Table 1 Biometric data for the 10 healthy volunteers recruited for the study: Gender male/female; body weight, W; height, H; body mass index, BMI. Pre-dose, P, maximum, M, and increase, (M-P), in breath methanol concentrations all in ppbv (rounded to nearest $10 \mathrm{ppbv}$ with uncertainties given as \pm ).

\begin{tabular}{cccccccrr}
\hline & \multicolumn{4}{c}{ Volunteer biometrics } & \multicolumn{3}{c}{ Exhaled methanol concentrations (ppbv) } \\
\hline No & Gender & Age & W [kg] & H [m] & BMI & P & M & (M-P) \\
\hline 1 & M & 47 & 100 & 1.80 & 31 & $190 \pm 17$ & $1310 \pm 28$ & $1110 \pm 45$ \\
2 & F & 21 & 80 & 1.67 & 29 & $340 \pm 19$ & $1630 \pm 30$ & $1290 \pm 49$ \\
3 & F & 29 & 65 & 1.80 & 20 & $190 \pm 17$ & $1180 \pm 27$ & $990 \pm 44$ \\
4 & F & 35 & 70 & 1.70 & 24 & $290 \pm 19$ & $1370 \pm 29$ & $1080 \pm 47$ \\
5 & M & 23 & 76 & 1.80 & 24 & $220 \pm 17$ & $1300 \pm 28$ & $1080 \pm 45$ \\
6 & M & 24 & 84 & 1.83 & 25 & $260 \pm 18$ & $1730 \pm 31$ & $1470 \pm 49$ \\
7 & F & 23 & 52 & 1.62 & 20 & $390 \pm 20$ & $1620 \pm 30$ & $1240 \pm 50$ \\
8 & F & 22 & 65 & 1.65 & 24 & $200 \pm 17$ & $1180 \pm 27$ & $990 \pm 44$ \\
9 & M & 23 & 59 & 1.72 & 20 & $260 \pm 18$ & $980 \pm 26$ & $720 \pm 44$ \\
10 & M & 22 & 76 & 1.77 & 24 & $440 \pm 20$ & $1290 \pm 28$ & $850 \pm 48$ \\
\hline
\end{tabular}


The increases in plasma methanol concentration due to aspartame ingestion reflect increases in both mouth-exhaled and nose-exhaled breath. It is instructive to compare these concentrations to ascertain if they are influenced by any other sources of variation. A plot of the nose-exhaled breath against the mouth-exhaled breath methanol concentrations obtained in the course of this study for various times before and after aspartame ingestion is shown in Figure 2. Note the close linearity of the lines with slopes of 0.87 and 0.93 . This indicates that the nose-exhaled methanol concentration is lower than the mouth-exhaled concentration by about $7 \%$. In our previous similar study involving just 3 healthy volunteers, the baseline nose-exhaled breath methanol was seen to be lower than the mouth-exhaled breath methanol variously by up to $6.5 \%$ [19]. The somewhat larger difference in the present cohort could be the result of small differences in nose sampling efficiency or perhaps some small methanol production in the oral cavity. It is also possible that the retention coefficient for methanol [33] is somewhat greater via the nose-breath track than via the oral cavity. Whilst the differences between oral and nasal concentrations are systematic, at a difference of only $7 \%$, either mouth-exhaled or nose-exhaled methanol measurements can be taken as corresponding to systemic methanol concentrations.

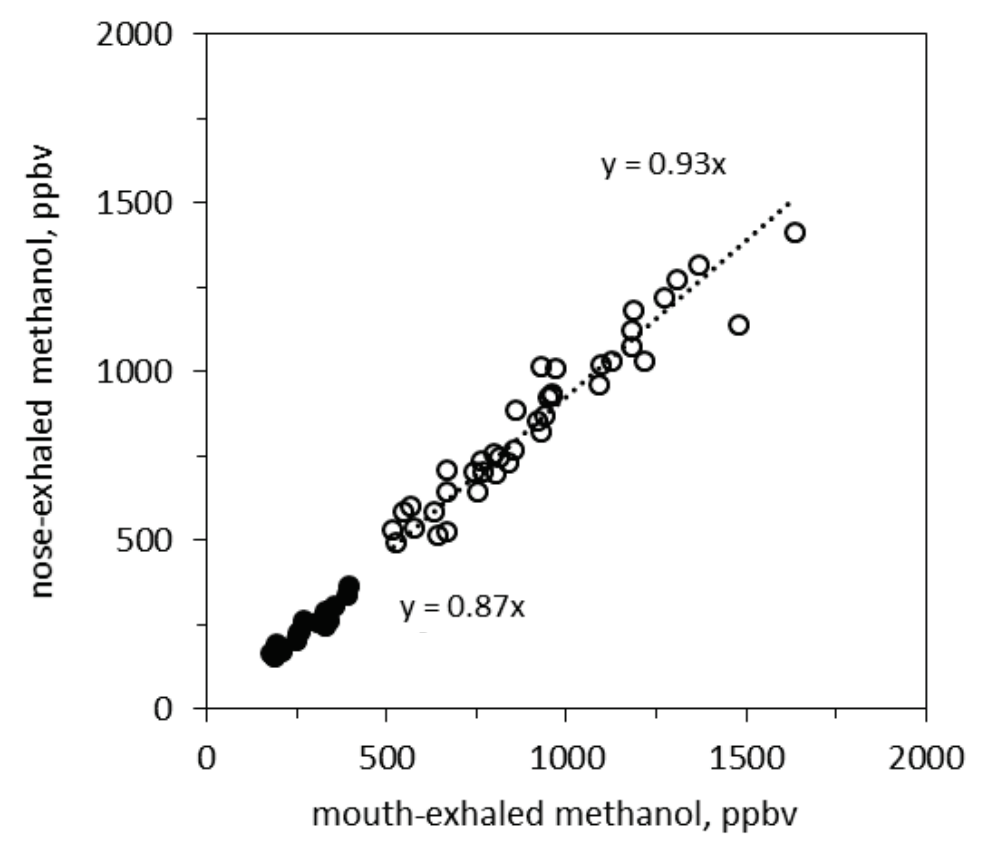

Figure 2 Plot of nose-exhaled against mouth-exhaled breath methanol concentration combining the data obtained before aspartame ingestion ( $\bullet$ black circles) and after aspartame ingestion ( $\circ$ open circles). 


\section{Discussion}

\subsection{Pre ingestion baseline concentrations}

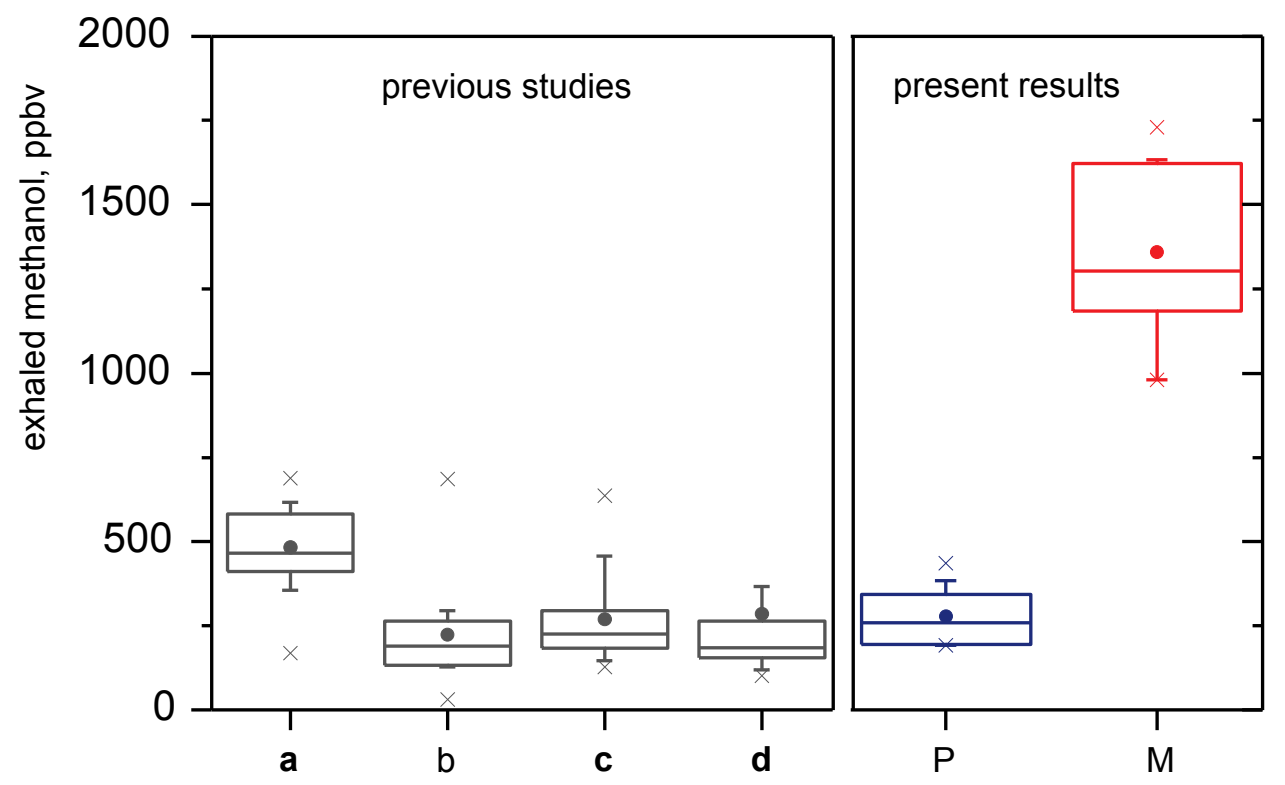

Figure 3 Box-and-whiskers plot of mouth-exhaled methanol mean concentration in ppbv obtained in previous SIFT-MS studies (a: Turner et al. 2006 [22], $\mathrm{n}=30$; b: Enderby et al. 2009 [르], $\mathrm{n}=200$; c: Spanel et al 2007 [23], $\mathrm{n}=26, \mathbf{d}$ : Cap et al. 2008 [18], $\mathrm{n}=34$ ) are given in the left block. The present mouth-exhaled methanol concentrations obtained before ingestion $(\mathrm{P})$ and the maximum concentrations after ingestion of aspartame (M) are given in the right block. Boxes indicate 25-75 percentile; horizontal lines indicate medians; whiskers indicate 10-90 percentile; data points $(\times)$ indicate minima and maxima of the ranges.

The distribution of the mouth-exhaled breath methanol concentrations as measured preingestion of aspartame in the present study is represented by a box and whiskers plot labeled $\mathrm{P}$ in the right block in Figure 3 where it can be compared with distributions obtained in previous SIFT-MS studies that are shown in the left block. The median age of the present cohort of 10 volunteers ( 5 females, 5 males) is 23 years (see Table 1) and the median breath methanol concentration is $261 \mathrm{ppbv}$. The longitudinal (inter-individual) study by Turner et al. 2006 [22] of mouth-exhaled methanol involved 30 healthy volunteers (11 females, 19 males, median age 47 years, range 24-59 years) over a period of 6 months (indicated as a in Figure 3) indicated a median concentration of $461 \mathrm{ppbv}$ [22]. The subsequent study of breath 
methanol of 200 children in the age range 7-18 years gave a median concentration of 193 ppbv (b) [24]), and a previous Prague study of 26 young adults age 17 to 18 years indicated a median mouth-exhaled methanol concentration of $238 \mathrm{ppbv}$ (c) [23]]). Finally, a study that focused on the comparison of direct exhalation methanol with volatiles released from exhaled breath condensate (11 males and 23 females, median age 41 years, range 25 to 62 years) resulted in a median exhaled methanol concentration of $189 \mathrm{ppbv}$ (d) [18]).

So there is acceptable consistency between the median values for the recent studies of cohorts $\mathbf{b}, \mathbf{c}, \mathbf{d}$ and $\mathbf{P}$ but the median value for cohort $\mathbf{a}$ is greater than these. Possible explanation for this difference is some variation in breath exhalation procedure, different volunteer age and the time-of-day when sampling was carried out. Dietary factors (British a, Czech d) may play a part, since it is generally assumed that endogenous methanol is produced by gut bacteria, so it is possible that higher endogenous methanol reflects an increased gut bacterial overload.

\subsection{Post aspartame ingestion concentrations}

Although each volunteer ingested an amount of aspartame according to their body weight, there are some differences in the maximum increases in breath methanol between the volunteers, as can be seen in Table 1. The observation of significant increase of the exhaled breath methanol concentrations as measured post-ingestion, labeled $\mathrm{M}$ in Figure 3, is very clear. Upon ingestion, the aspartame is metabolized producing the methanol, which then passes into the blood stream with minimal metabolic loss during the initial time frame involved in these studies (15 to 30 minutes) and equilibrates with total body water (TBW). The kinetics of equilibration between body compartments (blood, TBW) has been extensively investigated previously by tracing the time variation of the HDO content of exhaled breath following the ingestion of known amounts of $\mathrm{D}_{2} \mathrm{O}$ by cohorts of both health volunteers and patients with chronic kidney disease (CKD) [34]. These studies have consistently shown (by tracking breath HDO concentrations) that the blood stream/TBW equilibration takes only about 15 minutes to reach concentrations that are within about $90 \%$ of the ultimate equilibrium concentration, but takes 60 to 90 minutes to reach $1 \%$ of the equilibrium values that must be identified to accurately calculate TBW [35]. By analogy, the blood concentrations of methanol are within $10 \%$ of the TBW compartments concentrations of the individuals only about 15 minutes after aspartame ingestion. Thus, the observed methanol concentration reaches a peak value before appreciable metabolic loss occurs. 
The present data reveal that the average maximum increase in mean mouth-exhaled methanol concentration across the cohort is $1082 \pm 205$ ppbv above baseline concentrations. The expected increase in the breath methanol concentration can be predicted on the basis of a very simple one-compartment model: each ingested aspartame molecule produces one methanol molecule and after passing through the portal and systemic blood streams the methanol is uniformly dispersed into the TBW (includes the blood). On the basis of this one-compartment model, the breath concentration can be calculated as [36]:

$$
M-P=K V_{\mathrm{d}} / V_{\mathrm{TBW}}
$$

$M$ is the peak breath concentration of methanol, $P$ is the baseline breath concentration, $K=$ 0.177 is the dimensionless volumetric partition coefficient of methanol between blood and breath volume concentrations determined from the appropriate Henry's Law coefficient (that happens to be identical to ethanol [37]), $V_{\mathrm{d}}$ is the volume of liquid methanol corresponding to the ingested dose of aspartame and $V_{\mathrm{TBW}}$ is the total body water volume. If a simple estimate of TBW is taken as $60 \%$ of body weight of each volunteer [ $\underline{38}$ ], the value of $(M-P)$ calculated from equation (1) is the same for all volunteers, since the ratio of the aspartame dose to TBW is constant, and is revealed as $M-P=1032 \mathrm{ppbv}$. This estimate is remarkably close to the average experimental value of $1082 \pm 205$ ppbv supporting the validity of the single compartment model assuming that the dominant physiological process responsible for the initial increase in breath methanol is the dilution of the generated methanol in TBW prior to significant metabolic loss.

When combined with breath ethanol measurements following ethanol ingestion, TBW/breath measurements have been used to study first-pass metabolism of ethanol [36] and have shown that small doses of ethanol are metabolized exponentially with a time constant of typically 20 minutes, thus rapidly returning blood/breath ethanol to baseline levels in times of about 100 minutes [39]. In contrast to this, the present results clearly indicate that the metabolism of methanol is relatively slow. However, it should be noted that continued endogenous production of methanol by gut bacteria will slow down the net methanol loss. Thus, the slowly decaying portions of the breath methanol curves in Figure 1 and the relatively slow approach to baseline (pre-dose) levels has to be seen in terms of production and loss processes and so we do not attempt to estimate the metabolic loss rate of the methanol generated from the aspartame. 


\section{Concluding remarks}

This study revealed that aspartame ingestion at the ADI dose of $40 \mathrm{mg} / \mathrm{kg}(2.1$ to $4 \mathrm{~g}$ depending on the body weight of 10 individuals in the cohort) leads to significant increases of breath methanol concentration from pre-ingestion mean values ranging from 193 to $436 \mathrm{ppbv}$ to peak values ranging from 981 to $1622 \mathrm{ppbv}$. This implies that the corresponding blood methanol concentrations increase 3 to 6 times above the individual baseline values. This study also shows that the amount of methanol formed from ingested aspartame is rapidly dispersed and equilibrated throughout the total body water prior to its removal by metabolism and can thus be accurately quantified by breath analysis.

Methanol is present in the exhaled breath of all people largely due to colonic microbial production from unabsorbed complex carbohydrates. In this regard, it is interesting to note that it has been shown that restricting the ingestion of fruits and vegetables aimed at limiting potassium intake in dialysis patients effectively lowers the intake of dietary fibres, which in turn reduces endogenous methanol production and lowers its appearance in the exhaled breath [40]. Whilst the long term health effects of the increase of blood methanol concentrations resulting from ingestion of aspartame in addition to its endogenous production are not fully understood, it is important to note that it has been shown that accumulation of its possibly harmful metabolite formaldehyde occurs in the liver, kidneys, brain and other tissues [9].

This work is another demonstration that direct real-time analysis of even single breath exhalation, either via the nose or mouth, can be used to accurately determine the concentrations of breath trace gas metabolites, obviating sample collection into bags or onto traps with subsequent off-line analysis that potential complicates analysis [21]. The value of SIFT-MS real time analysis has also been well demonstrated by, for example, studies of breath ethanol and its metabolite acetaldehyde following the ingestion of alcohol [39] and by the TBW studies mentioned above [34, 41]. Nose/mouth exhaled breath studies can also distinguish between truly endogenous (systemic) compounds and those predominantly generated in the oral cavity, which is a necessary requirement as the topic of breath research progresses towards meaningful clinical diagnosis and therapeutic monitoring, as promoted and accelerated by the work of Professor Anton Amann to whose memory this paper is humbly and affectionately dedicated. 


\section{Acknowledgements}

We thank Professor Flégr for his help in obtaining ethics permission for this study and also the all volunteers who willingly enrolled into this study. We also thank the Czech Science Foundation GACR project number 13-28882S for financial support.

\section{References}

[1] Amann A and Smith D. Breath Analysis for Clinical Diagnosis and Therapeutic Monitoring. Singapore: World Scientific; 2005. p. 536.

[2] Amann A and Smith D. Volatile biomarkers: Non-Invasive Diagnosis in Physiology and Medicine. Elsevier; 2013.

[3] Butchko H H, Stargel W W, Comer C P, Mayhew D A, Benninger C, Blackburn G L, de Sonneville L M J, Geha R S, Hertelendy Z, Koestner A, Leon A S, Liepa G U, McMartin K E, Mendenhall C L, Munro I C, Novotny E J, Renwick A G, Schiffman S S, Schomer D L, Shaywitz B A, Spiers P A, Tephly T R, Thomas J A and Trefz F K 2002 Aspartame: Review of safety Regulatory Toxicology and Pharmacology 35 S1-S93

[4] Dorokhov Y L, Shindyapina A V, Sheshukova E V and Komarova T V 2015 Metabolic Methanol: Molecular Pathways and Physiological Roles Physiological Reviews 95 603-44

[5] Shaywitz B A, Sullivan C M, Anderson G M, Gillespie S M, Sullivan B and Shaywitz S E 1994 Aspartame, behavior, and cognitive function in children with attention-deficit disorder Pediatrics 93 70-5

[6] Magnuson B A, Burdock G A, Doull J, Kroes R M, Marsh G M, Pariza M W, Spencer P S, Waddell W J, Walker R and Williams G M 2007 Aspartame: A safety evaluation based on current use levels, regulations, and toxicological and epidemiological studies Critical Reviews in Toxicology 37 629-727

[7] Schernhammer E S, Bertrand K A, Birmann B M, Sampson L, Willett W C and Feskanich D 2012 Consumption of artificial sweetener- and sugar-containing soda and risk of lymphoma and leukemia in men and women Am. J. Clin. Nutr. 96 1419-28

[8] Humphries P, Pretorius E and Naude H 2008 Direct and indirect cellular effects of aspartame on the brain Eur. J. Clin. Nutr. 62 451-62

[9] Trocho C, Pardo R, Rafecas I, Virgili J, Remesar X, Fernandez-Lopez J and Alemany M 1998 Formaldehyde derived from dietary aspartame binds to tissue components in vivo Life sciences 63 337-49

[10] Davoli E, Cappellini L, Airoldi L and Fanelli R 1986 Serum Methanol Concentrations in Rats and in Men after a Single Dose of Aspartame Food and Chemical Toxicology 24 1879

[11] Sprung R, Bonte W and Lesch O M 1988 Methanol - a neglected constituent of all alcoholic beverages - a new biochemical approach to the problem of chronic-alcoholism Wiener Klinische Wochenschrift 100 282-8

[12] Stegink L D, Brummel M C, McMartin K, Martinamat G, Filer L J, Baker G L and Tephly T R 1981 Blood methanol concentrations in normal adult subjects administered abuse doses of aspartame Journal of Toxicology and Environmental Health 7 281-90 
[13] Stegink L D, Filer L J, Bell E F, Ziegler E E and Tephly T R 1989 Effect of Repeated Ingestion of Aspartame-Sweetened Beverage on Plasma Amino-Acid, Blood Methanol, and Blood Formate Concentrations in Normal Adults Metabolism-Clinical and Experimental 38 357-63

[14] Eriksen S P 1963 Methanol in normal human breath Science 141639

[15] Taucher J, Lagg A, Hansel A, Vogel W and Lindinger W 1995 Methanol in Human Breath Alcoholism: Clinical and Experimental Research 19 1147-50

[16] Lindinger W, Taucher J, Jordan A, Hansel A and Vogel W 1997 Endogenous production of methanol after the consumption of fruit Alcoholism: Clinical and Experimental Research 21 939-43

[17] Fenske J D and Paulson S E 1999 Human breath emissions of VOCs Journal of the Air \& Waste Management Association 49 594-8

[18] Cap P, Dryahina K, Pehal F and Španěl P 2008 Selected ion flow tube mass spectrometry of exhaled breath condensate headspace Rapid Commun. Mass Spectrom. 22 2844-50

[19] Wang T S, Pysanenko A, Dryahina K, Španěl P and Smith D 2008 Analysis of breath, exhaled via the mouth and nose, and the air in the oral cavity J. Breath Res. 2037013

[20] Michalčíková R B and Španěl P 2014 A selected ion flow tube study of the ion molecule association reactions of protonated $\left(\mathrm{MH}^{+}\right)$, nitrosonated $\left(\mathrm{MNO}^{+}\right)$and dehydroxidated $(\mathrm{M}-\mathrm{OH})^{(+)}$carboxylic acids (M) with $\mathrm{H}_{2} \mathrm{O}$ Int. J. Mass Spectrom. 368 15-22

[21] Smith D and Španěl P 2015 Pitfalls in the analysis of volatile breath biomarkers; suggested solutions and SIFT-MS quantification of single metabolites J. Breath Res. 9 022001

[22] Turner C, Španěl P and Smith D 2006 A longitudinal study of methanol in the exhaled breath of 30 healthy volunteers using selected ion flow tube mass spectrometry, SIFT-MS Physiol. Meas. 27 637-48

[23] Španěl P, Dryahina K and Smith D 2007 The concentration distributions of some metabolites in the exhaled breath of young adults J. Breath Res. 1026001

[24] Enderby B, Lenney W, Brady M, Emmett C, Španěl P and Smith D 2009 Concentrations of some metabolites in the breath of healthy children aged 7-18 years measured using selected ion flow tube mass spectrometry (SIFT-MS) J. Breath Res. 3 036001

[25] EFSA ANS Panel (EFSA Panel on Food Additives and Nutrient Sources added to food) 2013 Scientific Opinion on the re-evaluation of aspartame (E 951) as a food additive EFSA Journal 113496

[26] Španěl P and Smith D 2011 Progress in SIFT-MS: Breath analysis and other applications Mass Spectrom. Rev. 30 236-67

[27] Smith D and Španěl P 2005 Selected ion flow tube mass spectrometry (SIFT-MS) for on-line trace gas analysis Mass Spectrom. Rev. 24 661-700

[28] Smith D and Španěl P 2011 Ambient analysis of trace compounds in gaseous media by SIFT-MS Analyst 136 2009-32

[29] Smith D and Španěl P 2013 On the features, successes and challenges of selected ion flow tube mass spectrometry, SIFT-MS Eur. J. Mass Spectrom. 19 225-46

[30] Španěl P and Smith D 2013 Advances in On-line Absolute Trace Gas Analysis by SIFT-MS Curr. Anal. Chem. 9 525-39

[31] Španěl P, Dryahina K and Smith D 2006 A general method for the calculation of absolute trace gas concentrations in air and breath from selected ion flow tube mass spectrometry data Int. J. Mass Spectrom. 249 230-9 
[32] Španěl P and Smith D 2001 On-line measurement of the absolute humidity of air, breath and liquid headspace samples by selected ion flow tube mass spectrometry Rapid Commun. Mass Spectrom. 15 563-9

[33] Španěl P, Dryahina K and Smith D 2013 A quantitative study of the influence of inhaled compounds on their concentrations in exhaled breath J. Breath Res. 7017106

[34] Davies S J, Španěl P and Smith D 2014 Breath analysis of ammonia, volatile organic compounds and deuterated water vapor in chronic kidney disease and during dialysis Bioanalysis 6 843-57

[35] Smith D and Španěl P 2001 On-line determination of the deuterium abundance in breath water vapour by flowing afterglow mass spectrometry with applications to measurements of total body water Rapid Commun. Mass Spectrom. 15 25-32

[36] Wang T S, Španěl P and Smith D 2005 The combined use of SIFT-MS and FA-MS to investigate first-pass metabolism of ethanol. In: Amann A, Smith D, eds. Breath Analysis: for Clinical Diagnosis and ATherapeutic Monitoring Singapore: World Scientific Publ Co Pte Ltd) p. 479-90.

[37] Sander R 1999 Compilation of Henry's Law constants for inorganic and organic species of potential importance in environmental chemistry Mainz: Max-Planck Institute of Chemistry)

[38] Davies S J, Španěl P and Smith D 2001 Rapid measurement of deuterium content of breath following oral ingestion to determine body water Physiol. Meas. 22 651-9

[39] Smith D, Wang T S and Španěl P 2002 On-line, simultaneous quantification of ethanol, some metabolites and water vapour in breath following the ingestion of alcohol Physiol. Meas. 23 477-89

[40] Lee H J, Pahl M V, Vaziri N D and Blake D R 2012 Effect of Hemodialysis and Diet on the Exhaled Breath Methanol Concentration in Patients With ESRD Journal of Renal Nutrition 22 357-64

[41] Chan C, Smith D, Španěl P, McIntyre C W and Davies S J 2008 A non-invasive, online deuterium dilution technique for the measurement of total body water in haemodialysis patients Nephrol. Dial. Transplant. 23 2064-70 